\title{
Performance Enhancement of Solar Panels Using Adaptive Velocity-Particle Swarm Optimization (AVPSO) Algorithm for Charging Station as an Effort for Energy Security
}

\author{
Luthfansyah Mohammad ${ }^{1 *}$, Muhammad K. Asy'ari ${ }^{1}$, Mokhammad F. Izdiharrudin ${ }^{1}$, Suyanto ${ }^{1}$ \\ ${ }^{1}$ Department of Engineering Physics, Institut Teknologi Sepuluh Nopember \\ Kampus ITS, Sukolilo, Surabaya 60111, Indonesia
}

Received 3 July 2020; Accepted 19 August 2020

Available online 31 August 2020

\begin{abstract}
The growth of public awareness of the environment is directly proportional to the development of the use of electric cars. Electric cars operate by consuming electrical energy from battery storage, which must be recharged periodically at the charging station. Solar panels are one source of energy that is environmentally friendly and has the potential to be applied to charging stations. The use of solar panels causes the charging station to no longer depend on conventional electricity networks, which the majority of it still use fossil fuel power plants. Solar panels have a problem that is not optimal electrical power output so that it has the potential to affect the charging parameters of the battery charging station. Adaptive Velocity-Particle Swarm Optimization (AV-PSO) is an artificial intelligence type MPPT optimization algorithm that can solve the problem of solar panel power optimization. This study also uses the Coulomb Counting method as a battery capacity estimator. The results showed that the average sensor accuracy is more than $91 \%$ with a DC-DC SEPIC converter which has an efficiency of $69.54 \%$. In general, the proposed charging station system has been proven capable to enhance the energy security by optimizing the output power of solar panels up to $22.30 \%$ more than using conventional systems.
\end{abstract}

Keywords: AV-PSO, mppt, charging station, DC to DC SEPIC converter, coulomb counting, solar panel

\section{Introduction}

The growth of the human population has contributed to the high demand for world electricity supply. This increases the number of power generation needs in each country. In fact, electricity consumption is expected to increase by $130 \%$ by 2050 or by 55,000 TWh (IRENA, 2019). There are several types of power plants, including fossil fuel power plants and renewable energy power plants. Fossil energy power plants are economical and the most widely used power plants in the world, but there are shortcomings of these plants, one of which is the creation of waste substances in the form of radical pollution to the ground and into the air (Hankins, 2010). The amount of fossil energy power plants uses coal fuel by $27 \%$, natural gas by $24 \%$, and oil by $34 \%$ (IRENA, 2019). The pollutant raises several problems that have the potential to make environmental quality worse. Based on these problems, renewable energy power generation systems that are more environmentally friendly have been developed.

One type of renewable energy power plant is solar or photovoltaic panels. The solar panel system works by converting solar radiation to the results of DC electrical energy. Solar panels can be installed in almost any place, including locations that are close to the electricity load because of the ease of

\footnotetext{
* Corresponding author

E-mail address: luthfan48@gmail.com
} 
installation and use. Applications of solar panels have now been developed for charging stations (Gong et al., 2017). Charging stations are currently being built along with developments in the use of electric cars. The charging station is used as a place to recharge electric car batteries. There are several weaknesses of solar panels in their application, one of which is the intermittency of solar radiation conversion, especially at night (Arun \& Mohanrajan, 2019). Solar panels do not generate electricity at night so the installation of solar panels is equipped with batteries. The battery is one of the electrical components that can be used to store electricity. The battery must get an electric power supply that matches its characteristics so that the life-span of the battery can increase during charging conditions. Solar panels require a converter or Solar Charge Controller (SCC) to control the electrical power output in generating electricity for load requirements. In addition to using SCC, research on the improvement of charging station performance also includes the use of Internet of Things (IOT) (Akila et al., 2019), charging mode (Pavkovic et al., 2014), and the concept of fast charging (Moeini \& Wang, 2018).

SCC in general functions to regulate the output of electric power from solar panels to the battery, and one of these functions is Maximum Power Point Tracking (Mohammad et al., 2019). MPPT is a method used to optimize solar panel power output. MPPT requires an algorithm to be able to work in finding the most optimal solar panel output power (Suyanto et al., 2019). MPPT in SCC in general only uses a simple $\mathrm{P} \& \mathrm{O}$ type algorithm which in some cases has some weaknesses, such as the non-optimal value of the electrical power output of the solar panel and low tracking accuracy when partial shading occurs. Various artificial intelligence-based MPPT algorithms have been developed, one of which is the Adaptive Velocity Particle Swarm Optimization (AVPSO) algorithm. The AVPSO algorithm is a development of the PSO algorithm. The PSO algorithm is used to get a good equalization function in finding MPP values but the PSO algorithm has some disadvantages including acceleration characteristics, weight updates, and the absence of particle sorting in each iteration (Pragallapati et al., 2017). The AV-PSO algorithm has been proven to be able to track solar panel output power to the maximum and be able to solve partial shading problems with accurate tracking. Based on these problems, a hardware-based study is proposed with the title "Improving Solar Panel Performance Using the Adaptive Velocity-Particle Swarm Optimization Algorithm (AV-PSO) On Charging Station as an Effort for Energy Security". In this study, the independent variable used is solar irradiance level and duty cycle value, while the dependent variable is solar panel output power. Research has been done, and from the tests that have been done, AVPSO has worked well and can optimize the electrical power output in accordance with power tracking by using the duty cycle settings manually. In the end, AVPSO is an algorithm that can be used to optimize electrical power output at a charging station.

\section{Methods}

\subsection{Design Charging Station}

A charging station is a place used to charge electricity to a load. The charging station proposed in this study is to facilitate the presence of electric vehicles in charging, as shown in Figure 1. The charging station is designed using several components, namely solar panels, DC to DC SEPIC converters, and batteries. The algorithm used is in the form of AV-PSO as the MPPT algorithm and coulomb counting as a method of calculating battery capacity. The solar panel used has a capacity of $50 \mathrm{Wp}$ with polycrystalline type, DC to DC SEPIC converter with a capacity of $100 \mathrm{~W}$, and a battery with a capacity of 9 Ah with a terminal voltage of 12 volts. 


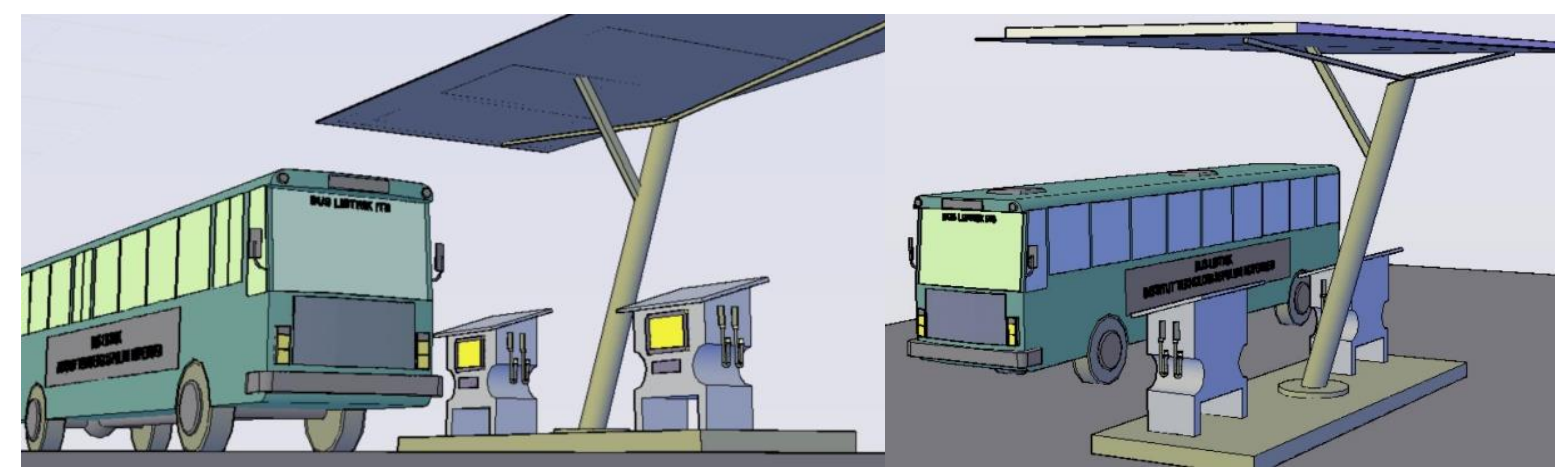

Figure 1. Charging station design.

\subsection{Solar panel and Maximum Power Point Tracking}

Solar panels are power plants that can produce electrical energy from the conversion of solar irradiation. Several main factors can affect the solar panel power output such as, the type of converter used, the electrical load being installed, the value of solar irradiation that illuminates the surface of the panel, and the temperature of the environment where the solar panel is installed (Gurfude \& Kulkarni, 2020). An important factor that can provide an important influence on the output of solar panel power is the result of the performance of the MPPT algorithm used. Solar panels emit electrical power with a certain pattern. The output power pattern can be represented on power to the voltage curve. Characteristic curves are used to determine the state of the peak point or MPP of the solar panel (Kumar, 2017). When the solar panel system has reached the peak point of the curve, it can be ascertained if the power output has been at its optimum point.

The Maximum Power Point Tracking (MPPT) method is one of the methods that actively work in finding the MPP conditions on the characteristic curve slope. When the solar panel system is in the MPP condition, the solar panel will also produce the most optimal power output. MPPT works using an algorithm as a control system. The control algorithm can do tracking by tracking the value of the voltage and electric current produced by solar panels which will then be calculated into power (watts). MPPT, through an optimization algorithm, will try to find the best value of power production from solar panels by changing the duty cycle value of the power converter. Changing the value of the right duty cycle on the power converter will make solar panels produce the most optimal electric power. MPPT will actively track the value of the duty cycle until the MPP value is obtained from the solar panel. The performance of MPPT can be determined from the quality of solar panel power output which can be assessed based on the accuracy and speed of MPPT in finding MPP. The combination of accuracy and good tracking speed will have a positive impact on the increasing value of the quality of the solar panel power and the overall quality of the solar panel system.

\subsection{Adaptive Velocity-Particle Swarm Optimization}

Particle Swarm Optimization (PSO) is one of the control methods that can be classified as a metaheuristic search algorithm that can be applied to quite diverse cases (Pragallapati et al., 2017). This algorithm adopts the behavior or natural characteristics of flocks of birds (particles). PSO is generally used to solve optimization problems in a specific area, by finding the best solution in that area. Several studies have conducted experiments using PSO in the MPPT case. The results show that if PSO manages to find the location of the MPP on the power characteristic curve of the voltage of the solar panel, the PSO has weaknesses, especially in some cases, for example, if used in the case of partial shading (nonuniform irradiation condition or NUIC).

Modifications are needed because of the characteristics and general PSO performance to solve the problem. Adaptive Velocity-Particle Swarm Optimization (AV-PSO) is an algorithm modified by conventional PSO. The modification of AV-PSO in the structure of the PSO algorithm is in the form of 
the magnitude and direction of the particle velocity vector. Changes were made to the weight factor and cognitive factor values. The existence of modifications to the weighting factor and cognitive factor algorithm, the particles will have a direction towards an optimal solution with rapid convergence. AVPSO optimization flowchart is shown in Figure 2.

In addition, in this study, a comparative data is presented as Table 1, where the performance of AVPSO shows that the algorithm can track without being trapped under local minima conditions, with variable parameter levels that are adaptive to irradiation changes, compared to some algorithms like conventional Particle Swarm Optimization, hybrid PSO, and several other types of optimization algorithms. In addition, this study also presented comparative data on the performance of the AVPSO algorithm with conventional PSO in the case of 4 peaks due to partial shading, where the AVPSO algorithm was able to optimize solar panel power output up to $99.62 \%$ superior to conventional PSO which was $99.56 \%$. This is intended if the AV-PSO algorithm can be used in tracking maximum power points both in ideal conditions and when solar panels are covered by shadows.

Table 1. Performance comparison results between AVPSO and other algorithms (Pragallapati et al., 2017).

\begin{tabular}{|c|c|c|c|c|}
\hline GMPPT Method & $\begin{array}{l}\text { No. of } \\
\text { parameters } \\
\text { required to be } \\
\text { set manually }\end{array}$ & $\begin{array}{l}\text { Do the particles } \\
\text { get trapped at } \\
\text { local minima? }\end{array}$ & $\begin{array}{l}\text { Are the } \\
\text { parameters }{ }^{1} \\
\text { adaptive? }\end{array}$ & $\begin{array}{c}\text { PV voltage } \\
\text { variations } \\
\text { during searching } \\
\text { process? }\end{array}$ \\
\hline $\begin{array}{c}\text { Conventional } \\
\text { PSO }\end{array}$ & 3 & Frequently & No & Present \\
\hline $\begin{array}{c}\text { PSO with } \\
\text { linearly varying } \\
\text { parameter }\end{array}$ & 3 & $\begin{array}{l}\text { Under some } \\
\text { NUIC patterns }\end{array}$ & $\begin{array}{l}\text { Limited } \\
\text { adaptivity }\end{array}$ & $\begin{array}{c}\text { Present } \\
\text { (depends on } \\
K_{\max } \text { ) }\end{array}$ \\
\hline $\begin{array}{c}\text { Deterministic } \\
\text { PSO }\end{array}$ & $1\left(\mathrm{w}_{\mathrm{i}}\right)$ & $\begin{array}{c}\text { Under some } \\
\text { NUIC patterns }\end{array}$ & No & Present \\
\hline Hybrid PSO & 3 & Frequently & No & Present \\
\hline $\begin{array}{l}\text { Non-PSO } \\
\text { method, } \\
\text { Simulated } \\
\text { Annealing }\end{array}$ & 1 & $\begin{array}{l}\text { Under some } \\
\text { NUIC patterns }\end{array}$ & No & $\begin{array}{c}\text { Present } \\
\text { (Drastic } \\
\text { variations in PV } \\
\text { voltage) } \\
\end{array}$ \\
\hline $\begin{array}{c}\text { Firefly } \\
\text { algorithm }\end{array}$ & 2 & - & No & Present \\
\hline $\begin{array}{c}\text { Artificial bee } \\
\text { colony }\end{array}$ & 2 & - & No & Present \\
\hline $\begin{array}{l}\text { Proposed } \\
\text { AVPSO }\end{array}$ & $1\left(c_{1}\right)$ & Never & Yes & $\begin{array}{c}\text { Smoothening } \\
\text { variations in PV } \\
\text { voltage }\end{array}$ \\
\hline Grey Wolf & 1 & - & $\mathrm{No}$ & Present \\
\hline
\end{tabular}

\subsection{State Of Charge (SOC) - (Coulomb Counting)}

State of Charge (SOC) is a benchmark for the value of battery capacity (He \& Guo, 2019; Tairov \& Stevanatto, 2011). SOC values are in the range of $0-100 \%$ which indicates the range of battery capacity. SOC is mathematically the ratio of the capacity at time $t\left(Q_{t}\right)$ compared to the nominal capacity of the battery $\left(Q_{n}\right)$. The SOC equation is displayed in equation (1).

$$
\operatorname{SOC}(t)=\frac{Q_{t}}{Q_{n}}
$$

SOC, in general, cannot be measured directly, so it requires an estimation method. The method used in this study is Coulomb Counting. Coulomb Counting is a method of estimating offline SOC by 
measuring the outflow or entry every hour. The SOC calculation equation with the Coulomb Counting method is shown in equation (2).

$$
\operatorname{SOC}(t)=\operatorname{SOC}\left(t_{0}\right)-\frac{1}{A h} \int_{t_{0}}^{t} i(t) d t
$$

$S O C(t)$ is the value of the current state of the battery charge, $S O C\left(t_{0}\right)$ is the value of the initial state of the battery charge with negative polarity (-) indicating if the battery is in a state of discharging and positive (+) indicates if the battery is charging, $i(t)$ is the value of the current that goes out or goes in every hour and $A h$ is the total battery capacity according to the datasheet. The graph of the battery SOC can be seen in Figure 3.

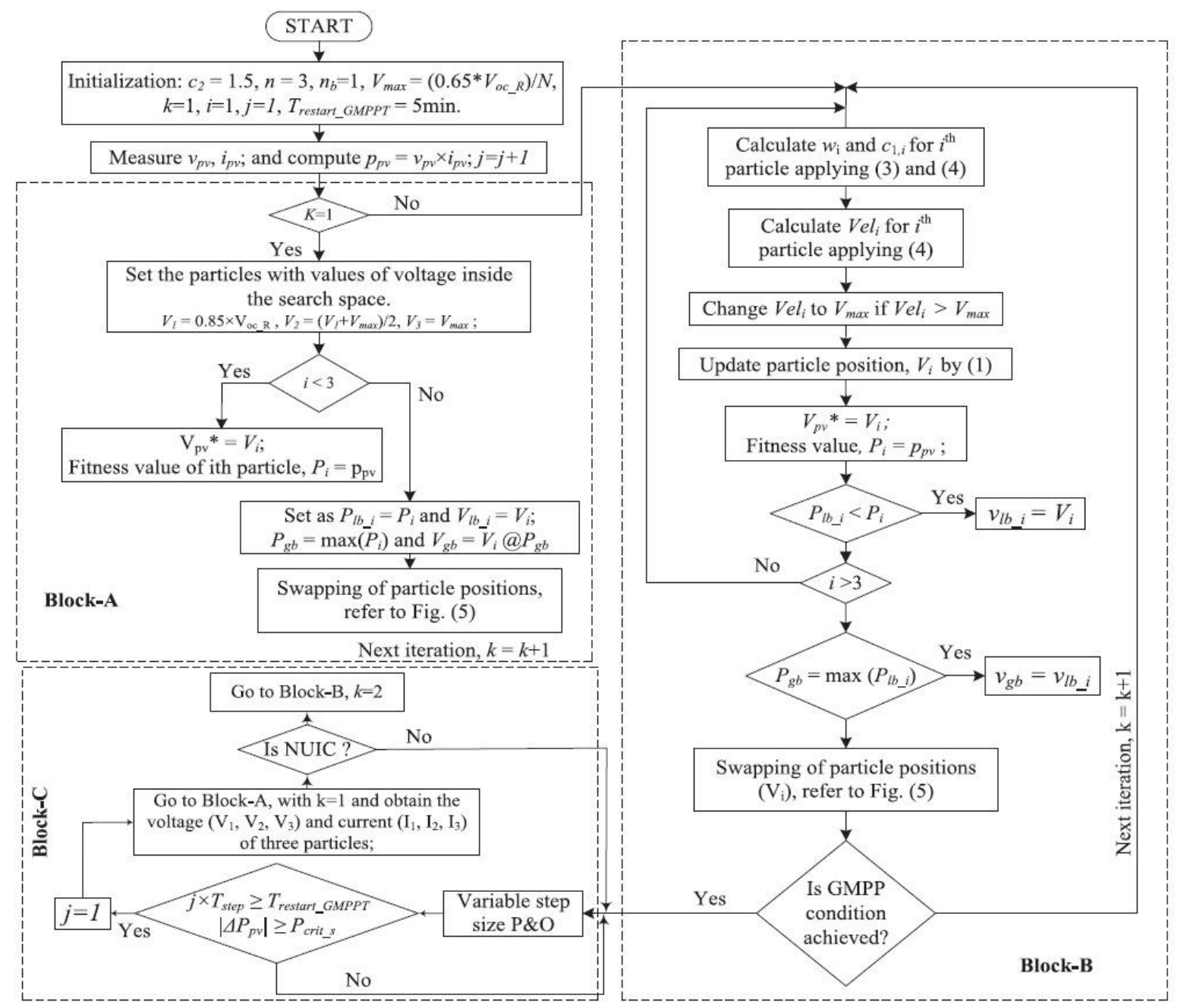

Figure 2. AV-PSO flowchart. 


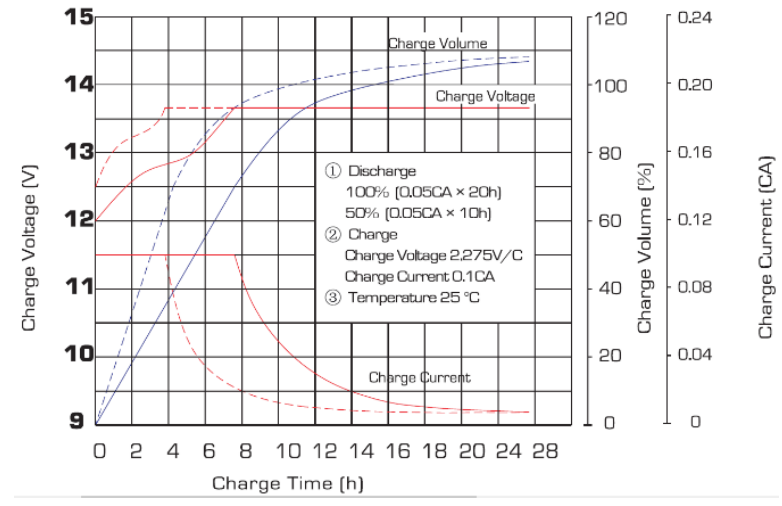

Figure 3. Battery charging graph.

\subsection{DC-DC Converter Tipe SEPIC}

SEPIC converter is a type of DC to DC converter that functions to change an input voltage rating to the output in a DC electrical system. DC to DC converter works by using the principle of electrical switching. The entire switching process is controlled based on the value of the duty cycle used. The duty cycle value can be determined through a pulse width modulation (PWM) signal from the microcontroller. The SEPIC converter in this study is used to convert the voltage from the solar panel as a converter input, to the battery voltage as output (Ilayaraja \& Narmadha, 2016; P \& Kumar, 2017). The voltage of the solar panel has a higher value than the battery terminal voltage so that the SEPIC converter will convert the higher input voltage to a lower output voltage. Besides, the intermittency of solar panels does not rule out the possibility that the solar panel voltage is lower than the battery voltage. This will make the converter have to increase the output voltage to the input voltage. There are several components used to design the SEPIC converter including two inductors $\left(L_{1,2}\right)$, two capacitors $\left(C_{1,2}\right)$, and a resistor $(R)$. The SEPIC converter circuit parameters used were $L_{1}$ of $183 \mu \mathrm{H}, L_{2}$ of $183 \mu \mathrm{H}, C_{1}$ of $4.33 \mathrm{mF}, C_{2}$ of $2.736 \mathrm{mF}, R$ of $5.6 \Omega$ and frequency $F$ of $40 \mathrm{kHz}$. The results of the SEPIC converter circuit hardware are shown in Figure 4.

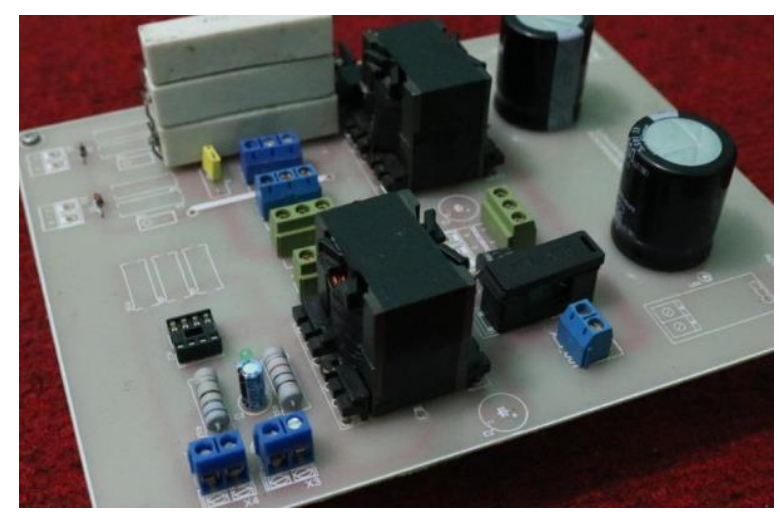

Figure 4. Results of SEPIC converter circuit hardware.

\section{Result and Discussion}

The test is carried out on several components that make up the overall system so that the performance of the system can be known and compared with the reference used. Analysis of work efficiency on each component is very important, because large or small values will be the main reference in the next process. 


\subsection{Characterization of Sensor}

The main sensors used in the system are the voltage sensor and the current sensor. The voltage sensor is used to determine the voltage value on the input and output side of the power converter. The voltage sensor plays an active role in determining the MPPT position in real-time. This device uses the principle of a voltage divider that is designed to divide the reference voltage with the input voltage as an Analog to Digital Converter (ADC) microcontroller voltage. Input and output voltage sensors will divide (decrease) the maximum reference voltage of $21 \mathrm{~V}$, to the maximum ADC voltage of $3.3 \mathrm{~V}$. The characterization of the two voltage sensors can be illustrated through the linearity and error graph in Figure 5. A multimeter is a measuring tool used as a standard reading (calibrator) on the measurement of input and output voltages. The voltage value is obtained from the reading of the voltage divider circuit, while the electrical current value of the system is obtained from the reading of the current sensor module. The sensor module used is ACS712 with a current capacity of 20 A.

Linearity equations for sensor input voltage, output voltage, input current, output current are shown in equation (3)-(6).

$$
\begin{aligned}
& \hat{V}_{i}=0.9796 V_{s}-0.0238 \\
& \hat{V}_{o}=0.9402 V_{s}+0.1568 \\
& \hat{I}_{i}=0.9912 I_{s}+0.0007 \\
& \hat{I}_{o}=0.9793 I_{s}+0.0256
\end{aligned}
$$

$V_{s}$ is the voltage source, $I_{s}$ is the source current, $\widehat{V}_{i}$ is the linearity input voltage, $\widehat{V}_{o}$ is the linearity output voltage, $\hat{I}_{i}$ is the current linearity input, and $\hat{I}_{o}$ is the linearity current output. Maximum error for the sensor input voltage is $1.60 \mathrm{~V}$ and the sensor output voltage is $2.70 \mathrm{~V}$. Maximum error for sensor input current is $0.25 \mathrm{~V}$ and sensor output current is $0.30 \mathrm{~V}$. Sensor input voltage accuracy is $94.05 \%$ and the sensor output voltage is $91.94 \%$ while accuracy sensor input current at $97.2 \%$ and sensor output current at $97.7 \%$.
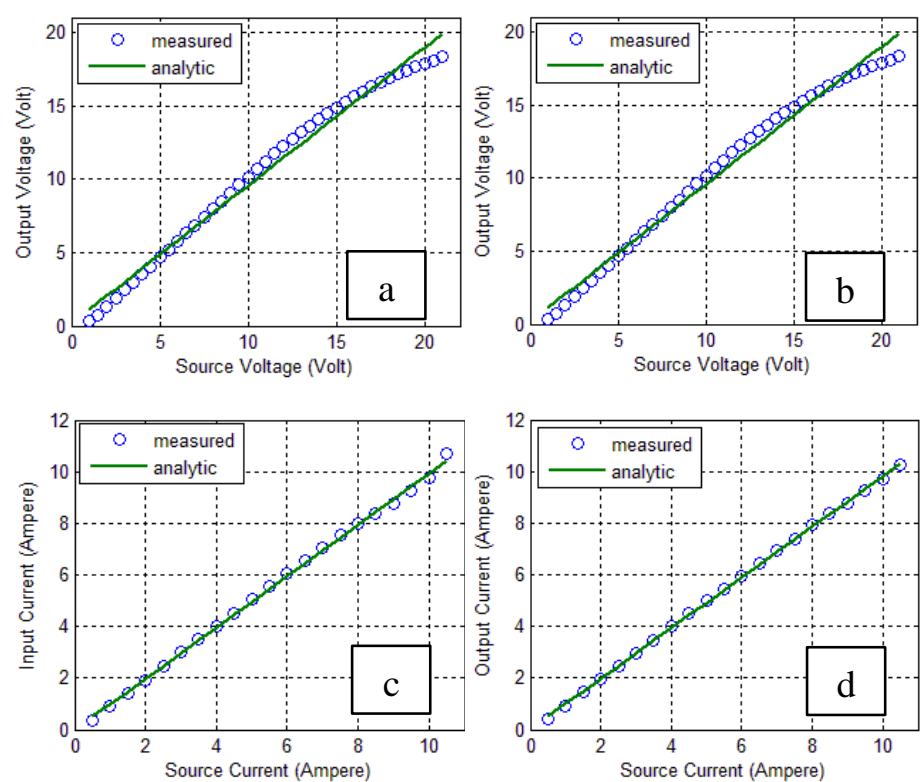

Figure 5. Graph of sensor characterization (a) input voltage, (b) output voltage, (c) input current, (d) output current.

\subsection{Characterization of SEPIC Converter}

The characterization of the SEPIC converter uses a $7 \mathrm{~V}$ with a resistor of $8.1 \Omega$. SEPIC characterization converts output voltage, output current, output power, and efficiency to changes in duty cycles. The graph of the SEPIC characterization results of the converter is tried in Figure 6. 

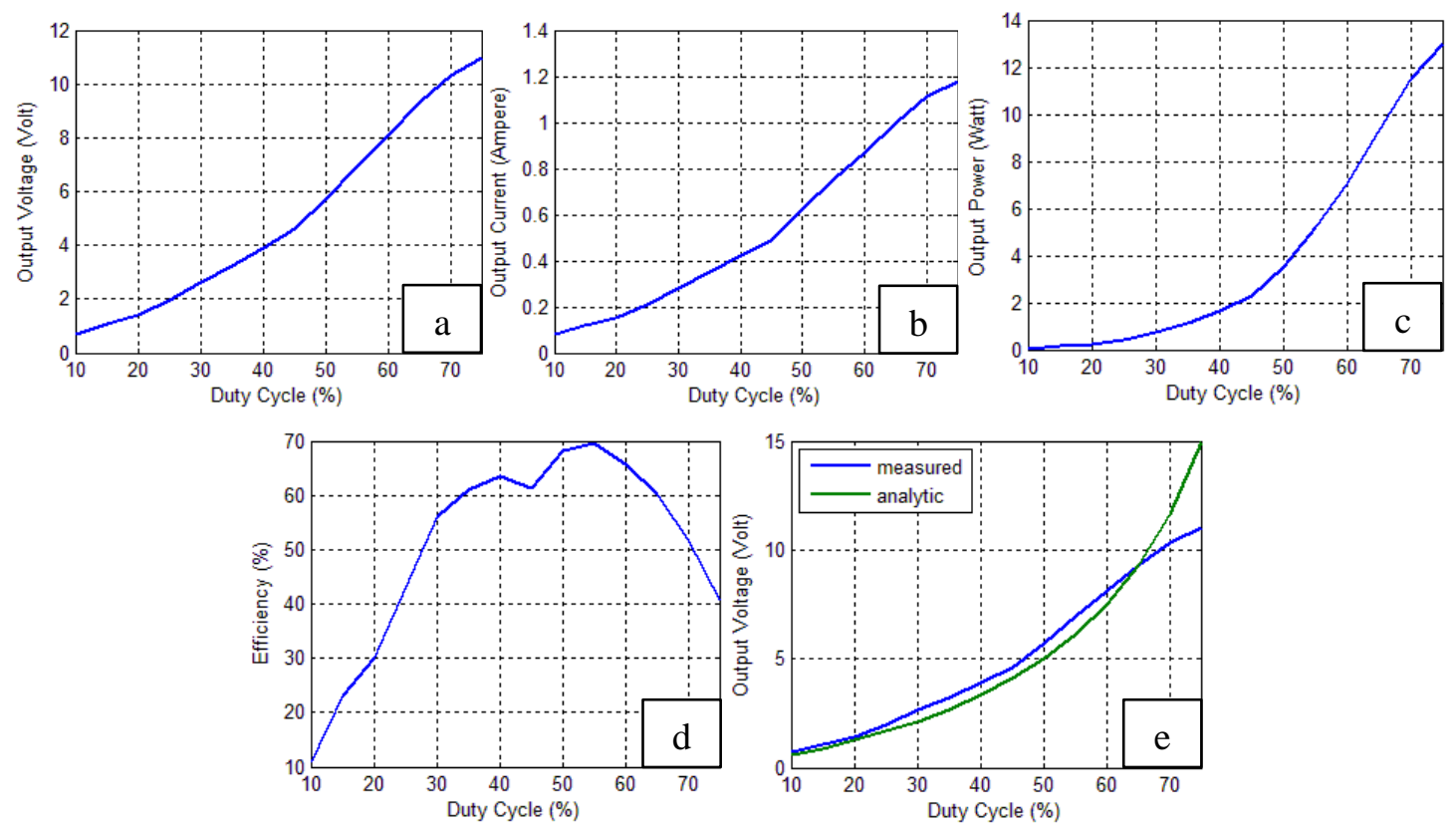

Figure 6. Graph of SEPIC converter characterization results (a) output voltage, (b) current output, (c) output power, (d) efficiency of duty cycle, and (e) comparative measured and analytic output voltage to the duty cycle.

Figure 6 shows the increase in the value of the duty cycle will increase the value of the voltage, current, and output power of the SEPIC converter. This is consistent with the tendency of the calculation results (Hart, 2011). The efficiency value refers to the maximum efficiency of $69.54 \%$ when the duty cycle is worth $55 \%$. The low-efficiency value is due to the capacity of the SEPIC converter used at $100 \mathrm{~W}$, while the SEPIC converter testing uses solar panels with a capacity of $50 \mathrm{~W}$. There is a difference between the measured output voltage and the calculated output voltage. The biggest error of $4.00 \mathrm{~V}$ which occurred at $75 \%$ duty cycle.

\subsection{Results of Maximum Power Point Tracking with the AV-PSO Algorithm}

Characterization of solar panels using solar irradiance variations with values of 400,600,800, and 1,000 $\mathrm{W} / \mathrm{m}^{2}$. Each variation is given a duty cycle value in the range of $10-70 \%$ with an interval of $2 \%$ to get power input. A graph of the relationship between the input voltage and solar panel power input with variations of solar irradiation in Figure 7.
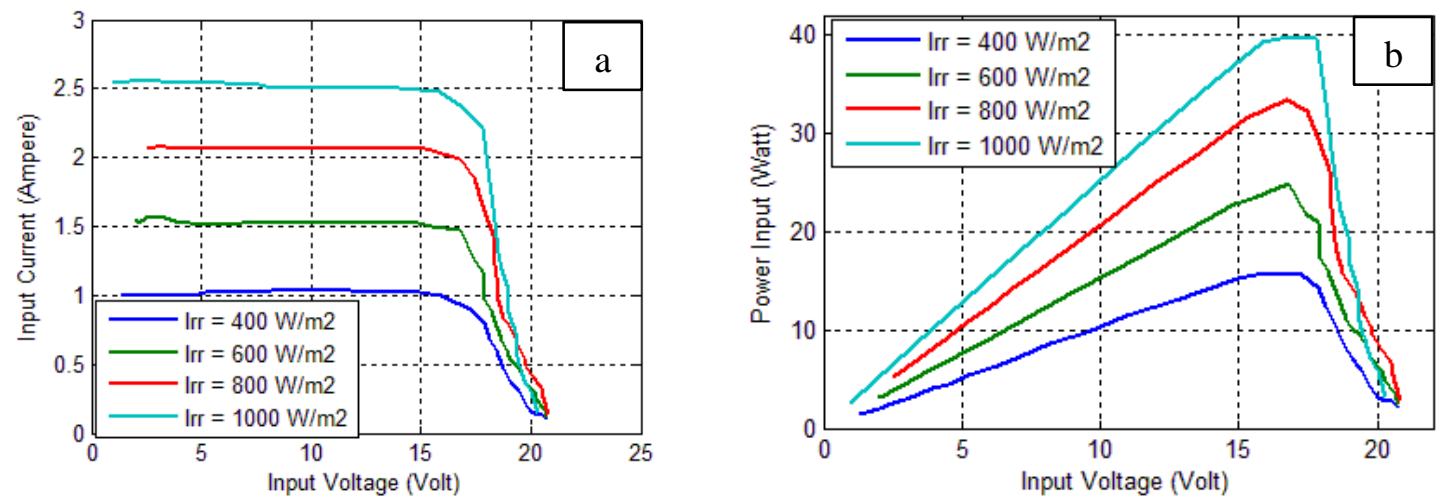

Figure 7. Graph of the relationship between input voltage with (a) current input and (b) solar panel power input with solar irradiance variations.

Figure 7 shows the maximum input power value of $15.89 \mathrm{~W}$ for solar irradiance of $400 \mathrm{~W} / \mathrm{m}^{2}, 24.83 \mathrm{~W}$ for solar irradiance of $600 \mathrm{~W} / \mathrm{m}^{2}, 33.33 \mathrm{~W}$ for solar irradiance of $800 \mathrm{~W} / \mathrm{m}^{2}$, and $39.91 \mathrm{~W}$ for solar 
irradiance of $1,000 \mathrm{~W} / \mathrm{m}^{2}$. This shows that solar panels have a maximum power point in each solar irradiance value. Tracking the maximum power point value can be determined automatically via the AV-PSO algorithm. The MPPT system on solar panels can increase input power by an average of $22.30 \%$. The results of maximum power point tracking with the AV-PSO algorithm are shown in Table 2.

Table 2. Results of maximum power point tracking with the AV-PSO algorithm.

\begin{tabular}{|c|c|c|c|c|}
\hline \multirow[b]{2}{*}{$\begin{array}{l}\text { Solar Irradiance } \\
\qquad\left(\mathrm{W} / \mathrm{m}^{2}\right)\end{array}$} & \multicolumn{2}{|c|}{ MPPT System } & \multirow{2}{*}{$\begin{array}{c}\text { Conventional System } \\
\text { Power Input } \\
\text { (W) }\end{array}$} & \multirow[b]{2}{*}{$\begin{array}{l}\text { Increased Power } \\
\text { Solar Panel }(\%)\end{array}$} \\
\hline & $\begin{array}{c}\text { Duty Cycle } \\
(\%)\end{array}$ & $\begin{array}{l}\text { Power Input } \\
\text { (W) }\end{array}$ & & \\
\hline 400 & 33.8 & 16.81 & 13.67 & 18.68 \\
\hline 600 & 39.0 & 25.13 & 18.62 & 25.91 \\
\hline 800 & 42.0 & 33.50 & 25.99 & 22.42 \\
\hline 1,000 & 44.6 & 41.03 & 31.93 & 22.18 \\
\hline
\end{tabular}

\subsection{Results of Charging Performance}

The system is tested in integration or together after it is known if each component has been able to work partially. The battery is charged for 220 minutes with changes in current and voltage parameters according to the charging chart in Figure 8.

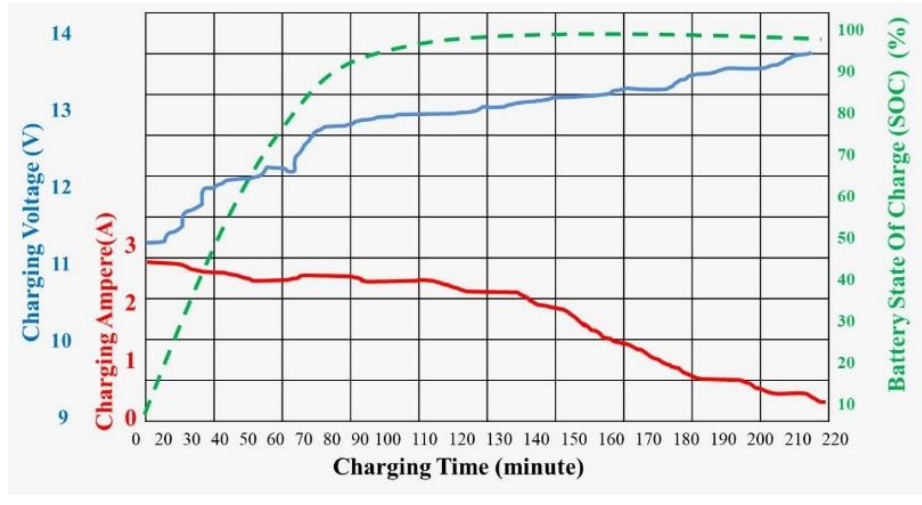

Figure 8. Graph of charging system test results.

\section{Conclusion}

The test results show that the constituent elements of the charging station have worked well. The sensor system has worked and has an accuracy above $91 \%$. The DC to DC SEPIC converter has been partially tested and integrated with good efficiency. In total, the system has worked well and proven to be able to increase the output power of solar panels up to $22.30 \%$ compared to conventional systems. Changes in solar irradiance will result in changes in the output power of solar panels, the greater the value of solar irradiance, the greater the output power of solar panels. Solar irradiance variations given are 400, $600,800,1,000 \mathrm{~W} / \mathrm{m}^{2}$. Increased solar panel power generated by $18.68 \%, 25.91 \%, 22.42 \%$, and $22.18 \%$ with solar irradiance kneeling in a row of $400,600,800,1,000 \mathrm{~W} / \mathrm{m}^{2}$. The increase in solar panel power is between $18.68-25.91 \%$. So, it can be concluded if the proposed charging station system can enhance the possibility of energy security more than the conventional charging station system. 


\section{References}

Akila, A., Akila, E., Akila, S., Anu, K., \& Elzalet, J. (2019). Charging station for e-vehicle using solar with IOT. 20195 th International Conference on Advanced Computing and Communication Systems, ICACCS 2019, 785-791. Retrieved from: https://doi.org/10.1109/ICACCS.2019.8728391

Arun, P. S., \& Mohanrajan, S. R. (2019). Effect of partial shading on vehicle integrated PV system. Proceedings of the 3rd International Conference on Electronics and Communication and Aerospace Technology, ICECA 2019, 1262-1267. Retrieved from: https://doi.org/10.1109/ICECA.2019.8821888

Gong, L., Cao, W., \& Zhao, J. (2017). Load modeling method for EV charging stations based on trip chain. 2017 IEEE Conference on Energy Internet and Energy System Integration, EI2 2017 Proceedings, 2018-January, 1-5. Retrieved from: https://doi.org/10.1109/EI2.2017.8245572

Gurfude, S. S., \& Kulkarni, P. S. (2020). Energy yield of tracking type floating solar PV plant. 2019 National Power Electronics Conference (NPEC), 1-6. Retrieved from: https://doi.org/10.1109/npec47332.2019.9034846

Hankins, M. (2010). Stand-alone solar electric systems: The earthscan expert handbook for planning, design and installation. Earthscan.

Hart, D. W. (2011). Power electronic. Tata McGraw-Hill Education.

He, L., \& Guo, D. (2019). An improved coulomb counting approach based on numerical iteration for SOC estimation with real-time error correction ability. IEEE Access, 7, 74274-74282. Retrieved from: https://doi.org/10.1109/ACCESS.2019.2921105

Ilayaraja, S., \& Narmadha, T. V. (2016). Modeling of an e-vehicle charging station using DC-DC selflift SEPIC converter. 2016 2nd International Conference on Science Technology Engineering and Management, ICONSTEM 2016, 526-531. Retrieved from: https://doi.org/10.1109/ICONSTEM.2016.7560949

IRENA. (2019). Climate change and renewable energy: National policies and the role of communities, cities and regions (Report to the G20 climate sustainability working group (CSWG)). Retrieved from: www.irena.org

Kumar, S. (2017). Ant colony optimization for less power consumption and fast charging of battery in solar grid system. 244-249.

Moeini, A., \& Wang, S. (2018). Design of fast charging technique for electrical vehicle charging stations with grid-tied cascaded H-bridge multilevel converters. Conference Proceedings - IEEE Applied Power Electronics Conference and Exposition - APEC, 2018-March(1540118), 3583-3590. Retrieved from: https://doi.org/10.1109/APEC.2018.8341621

Mohammad, L., Prasetyono, E., \& Murdianto, F. D. (2019). Performance evaluation of ACO-MPPT and constant voltage method for street lighting charging system. Proceedings - 2019 International Seminar on Application for Technology of Information and Communication: Industry 4.0: Retrospect, Prospect, and Challenges, ISemantic 2019. Retrieved from: https://doi.org/10.1109/ISEMANTIC.2019.8884303

P, D., \& Kumar, K. R. (2017). MPPT based control of sepic converter using firefly algorithm for solar $P V$ system under partial shaded conditions. 1-8.

Pavkovic, D., Lobrovic, M., Hrgetic, M., Komljenovic, A., \& Smetko, V. (2014). Battery current and voltage control system design with charging application. 2014 IEEE Conference on Control Applications, CCA 2014, 1133-1138. Retrieved from: https://doi.org/10.1109/CCA.2014.6981481

Pragallapati, N., Sen, T., \& Agarwal, V. (2017). Adaptive velocity PSO for global maximum power control of a PV array under nonuniform irradiation conditions. IEEE Journal of Photovoltaics, 7(2), 624-639. Retrieved from: https://doi.org/10.1109/JPHOTOV.2016.2629844

Suyanto, S., Mohammad, L., Setiadi, I. C., \& Roekmono, R. (2019). Analysis and evaluation performance of MPPT algorithms: Perturb observe (PO), firefly, and flower pollination (FPA) in smart microgrid solar panel systems. 2019 International Conference on Technologies and Policies in Electric Power and Energy, TPEPE 2019. Retrieved from: https://doi.org/10.1109/IEEECONF48524.2019.9102532

Tairov, S., \& Stevanatto, L. C. (2011). The novel method for estimating VRLA battery state of charge. Proceedings - 2011 IEEE Electronics, Robotics and Automotive Mechanics Conference, CERMA 2011, 211-215. Retrieved from: https://doi.org/10.1109/CERMA.2011.40 